\title{
Memories That Reach Back into Consciousness: An Interview with Lan Samantha Chang
}

Lan Samantha Chang was born and raised in Appleton, Wisconsin, the daughter of Chinese parents who survived the Japanese occupation of China and subsequently migrated to the United States. Her parents didn't share extensive information about their experiences in their homeland, and in writing the novel Inheritance (2004), Chang had the opportunity to do research into the world her parents had once inhabited. Inheritance tells the story of a splintered Chinese family set against the historical backdrop of the 1920 s to 1940s. The schism that divides sisters Junan and Yinan mirrors the fate of China during this time.

In Hunger: A Novella and Stories (1998) Chang focuses on Chinese immigrants and their children, who labor for emotional survival. The families in this novella and collection of stories accomplish a fragile balance between remembering and forgetting their past, and starting over on foreign soil. The title novella is narrated after her death by Min, whose husband escaped from China swimming with his precious violin held high above his head.

In January 2006, Ms. Chang was appointed Professor of English and Director of the Writers' Workshop at the University of Iowa.

Sherry Ellis: "My family story is like a stone," Hong, the narrator of Inheritance, says. "I often think about its true dimensions, weight, and shape. Many years ago it was pitched into deep water, pulling after it a spout of air, leaving only ripples." Hong worries history will repeat itself, that her family's legacy of unhappiness and betrayal has been passed onto her by her mother and grandmother. Throughout Inheritance the reader's senses are powerfully evoked by symbols of nature. How did you choose to contrast nature and betrayal, nature and love, throughout this novel?

Lan Samantha Chang: I've become very interested in the natural world in the last several years. My husband, Robert Caputo, is a landscape painter and as a result of accompanying him on his plein- 
air expeditions I have been introduced to the woods of Maine, as well as various lovely parts of New England and the Southwest. Although I wasn't working on nature writing at the time, what I saw and and experienced on these expeditions found its way into my novel in figurative language that was able to reach across cultures.

SE: You've said that Inheritance is an "imaginary history-an exploration into lives that might have been." Can you describe what you mean by this phrase and the extent to which this novel is an imagined biography, an imagined history of your family?

LSC: Inheritance is about an imaginary family, but in writing I applied some of the same techniques to this imaginary family that have been useful to me in learning my own family history. The narrator, Hong, says that every child is born into the middle of a story she doesn't know. As children many of us spend an enormous amount of imaginative energy trying to detect or trace out things that happened before we came to be. I think it's natural to a thoughtful person to engage in this activity, and particularly for children of immigrants, like myself, who don't have experience of the old country. The quest to know their parents comes from a place to understand not only the parents but the culture, the world. There's a part of the world that our parents inhabited and we're trying to seek it out in a very powerful way because we've never experienced it. It's a strange, unknown piece of the past; it's a personal myth.

Hong is a detective. She's trying to understand how things came to be. She's struggling to untie this complicated knot of the love affair in her mother's generation because it has such a strong effect on her as a person and on her development as a person, on the person she becomes. In that way I think that my own need to understand my family and Hong's quest to understand her family are very similar.

My parents were born in China and lived through the turbulent period Hong describes in the book. They left China in 1949 when Mao took over and moved through Taiwan, then to the United States. In 1949 there was a cut-off between mainland China and much of the world that lasted almost thirty years, and it was during that time when I was born and raised. I grew up with a sense that China was unreachable. I also sensed that the country was enor- 
mously central to my parents. And that the loss of leaving China and coming through space and time to Appleton, Wisconsin was so significant and painful, perhaps, that in order for me to understand my parents at all I had to know what had happened in the past, when they were growing up, in China. I think that's where the idea of the "imagined history" comes from.

SE: I read that you focused on East Asian studies during your undergraduate years. It sounds as though you fed your left brain information about the time period your parents lived through, and then fed your right brain by applying this knowledge to your fictional works.

LSC: I went through a period in my life where it seemed important to study the facts. I majored in East Asian studies and took a lot of Chinese. But I didn't use any of it, in a practical sense, until I came to write, at which point it was there for my imagination to use. And even so, I wrote one story about China in 1993 and didn't write about China again in an active way until I started Inheritance.

SE: Inheritance is set in the China of the 1930s and 1940s, when the country was being invaded by Japan, when it was plagued by Communist revolutionaries. What opportunities do you think this particular period in history, this backdrop, provided you as a writer and the circumstances you were able to provide to your characters?

LSC: The circumstances of the book are very dramatic. There's a death by beheading. There's a birth in a bomb shelter. There's a bridge collapsing and hundreds of civilians falling into a chasm on the border of China and Burma. The characters make dramatic moves across country to escape encroaching death. The historical events of China provided amazing material for me as I tried to write my book and they were also quite challenging for me, trained as I was in contemplative American realism. I had to adapt my language and sensibility to encompass sweeping historic and cataclysmic events.

One of the influences on Inheritance that no one has mentioned is the Chinese drama and particularly the television drama that Chinese people and immigrants such as my parents watch all the time. I haven't sat through many of them because they're intensely 
long, DVD after DVD of these sagas, many of them historical, whose stories sometimes take place over many years and are melodramatic as all get-out. They are historical soap operas for people of Chinese descent. They fictionalize well-known historical characters and dramatize the terrible trials they've gone through. There are always deaths and torture scenes. In writing Inheritance, I borrowed from this sensibility.

SE: I understand that as you wrote Inheritance you threw away four hundred pages and rewrote it fourteen times. How did you ultimately decide the form of this novel, and what to tell and not to tell?

LSC: When I began drafting the book, I knew I wanted to have the younger sister and the older sister's husband fall in love, and I knew that I wanted to end the book with a funeral, but all the other scenes in the book were as yet undiscovered to me.

I began by writing short stories, and for many years, I had a problem when I tried to write long work. Instead of moving on I would collect a few pages and obsess over the task of trying to perfect a short passage of prose. I needed to break this pattern in order to write through the arc of a story. I decided to set a goal in 1998 to write ten pages of draft a week. My trick: after every hundred pages I closed the file and did not allow myself to look at what I had written. I knew that if I looked back, I would cease to move forward. That year, I had some interruptions but I did finish 450 pages of draft-and they were terrible.

Now that I've finished the book, I think of that horrible first draft and find it interesting that it does contain many of the significant scenes that went into the center of the final product. For years, I didn't know how to tell the story to get to these events, and I certainly didn't know what the characters would do after they took place; figuring that out was very challenging. The framing of the central drama was the most difficult for me. Building the narrative arc of the novel was also hard. I had never designed a long narrative and it took a lot of patient effort. I drafted those 450 pages in a year and spent five more years trying to figure out how to use the best pieces of that draft, and how to fit the pieces together. 
I had a fellowship at Princeton and I wrote 150 pages that year. It was all about Junan's father's gambling, and that whole generation: how they got into the situation they were in, and who he was and whether he had a mistress; in this draft he did and her name was Swallow and she was a courtesan. I gave the pages to my editor and to a friend, Elizabeth Rourke, who always reads my work, and they both said the same thing: that the book didn't really get going until about a hundred pages in. I had to take out 150 pages, almost everything I had written that year. Doing this, I had the wonderful sensation a snake must have when it is sloughing off an old, no longer necessary skin.

The next year I had another fellowship. I felt so lucky, and because I had shed the unnecessary parts of the first half, I was able to see the story line. I wrote through, got a lot of the first half down to what exists in the final draft. I reached the cave scene and the birth of the son, and then got stuck again. I could not get past the complication of the son being born, and wrote all the way to the end at least seven or eight times. In almost every version Hong, the narrator, had a different fate. It was like a "choose your own adventure" book-whom she married, whether she married, how many children she had. One of the other big changes I had to work through was whether Li Ang would come to the U.S. I couldn't find enough narrative energy to last through the U.S. years of the novel. I cut another 150 pages plus the fifty more pages in the middle. I feel good about all this now. I spent so much time working through the alternatives that I'm confident I chose the right one. I just couldn't see the shape of it until I had worked through it so many times.

SE: In the novella "Hunger" you write, "My senses opened; I grew large. I believed I heard in the howling wind, a voice of admonition, but in the end I listened to the plunge and whistle of my blood. I put the hat into his beautiful, long-fingered hands." This powerful description is wed to a description of yuanfen, a Chinese word that means fate, "that apportionment of love which is destined for you in this world." Min's fate is to have a love unfulfilled. How did you develop her character?

LSC: Well, that's an interesting story. When I set out to write "Hunger," I had one goal in mind: to write something that was lon- 
ger than twenty-five pages; until then I had written only short stories. Some of the short stories were fairly polished; one was in Best American Short Stories. But I knew I was incapable of writing a long narrative. I failed in repeated attempts to do this, so I decided on a medium-sized narrative; I thought that a novella might be possible.

I decided to take a short story of mine, "The Eve of the Spirit Festival," a story in which there was a dynamic that I trusted: a father and two sisters, one who was favored and one who was not. I knew I understood it. I decided to take this dynamic and put it into something longer. I added more characters, the mother, and the music. I had studied violin as a child and I had taught it as an adolescent through my twenties for pocket money. With all this in mind I started with the plan to write from the point of view of one of the daughters. I hammered out some scenes and I could tell that they were lackluster, but I didn't know why. I was forcing myself to write forward because I knew my tendency to obsess over sentences and paragraphs. So I drafted all these thin, boring scenes. I had set a deadline for myself, the end of the summer, and it was already July. Everything felt so desperate and something was wrong, but I didn't know how to fix it.

My mother knew about this project and I told her about this problem. I told her I suspected it was a problem with the point of view. She asked me to describe what "point of view" was, and after I explained it to her, she asked why I didn't tell the novella from the mother's point of view. Now I always smile when I think about this, because of course she would suggest the mother's point of view, but, like many mothers, she was right. After she made this suggestion I redrafted the long scene when Anna is trying to please Tian by playing the Bach Double Concerto and she is failing, and then her younger sister Ruth comes in and ends up being much more talented. I rewrote it from the mother's point of view. I still remember this day. It was early August. I was in the LAIR, the big computer center at Stanford, where I often went to write so I didn't spend my whole day alone in my apartment-I found a certain security in the anonymity of writing in that big room, surrounded by students working on their programming assignments. And as I was typing I could feel the story gather under my hands and take on life. It was as if it literally started to breathe. From that point onward it was much more clear. I finished drafting "Hunger" by the end of September. 
SE: In this relatively short time you wove so many manifestations of hunger into the novella, in terms of description, simile, behavior, metaphor.

LSC: Sad to say, I don't know how much of it was conscious. I think it's just that if you're writing something that strikes a deep vein, if you find the place from which your story is coming, you find the place where everything is connected. If only you can get to that place. Great artists are the ones who do it on a regular basis. It's not the kind of thinking you can figure out by using your critical faculties.

SE: It seems possible that the circumstances facing Sansan and Ming Hwang in your short story "The Unforgetting" could bear witness to the experience of your own family. In this particular story a married couple settles in Iowa, the father gives up his dream of being a scientist and becomes a photocopy repairman, the wife cooks using American food and Betty Crocker recipes, they store six rice bowls once used in the emperor's household in their basement. How much of your motivation in writing this and other stories that deal with immigration and loss through assimilation has to do with your own family's experience?

LSC: That story is in some ways very similar to the story of my family. My parents moved their family out to the Midwest, as pioneers, into a culture nothing like the culture they had come from. There's a sense of great unity and great deprivation in such families. However, in "The Unforgetting" San and Ming try to repudiate their Chinese culture, whereas my family did not. They encouraged us to be proud of the fact that we were Chinese and to maintain our Chinese culture, and yet I could feel it slipping though my fingers the minute I left home to go to kindergarten. I lost my Chinese and began to speak only English. At school I saw ways of looking at and thinking about things that were better for me as an individual. I think all of those issues get woven into the story but they are distorted. The idea of memories flooding back into consciousness is true of our family certainly, but I think of that as a human trait, and not only true of my family. The idea of the child leaving home and running away to school, leaving his parents, the great pain of 
that, is something that took place in my family but in a completely permitted and voluntary way. My parents didn't want us to stay in the Midwest for our whole lives. They wanted us to go out in the world and seek our fortunes, to go the East Coast, and all four of us did. It was an American success story, but that doesn't mean it wasn't painful. I think of this story as about being Asian parents in the western world.

SE: With the fortunate start of having your second story published in The Atlantic Monthly, how much internal pressure did you subsequently experience as a writer to perform and rise up to that level?

LSC: It was pretty intense, although I didn't understand how much so at the time. Luckily I had other stories I was working on at the time; "San" was more important to me than the story that was in the Atlantic. In fact "San" is still my favorite story. What happened was I spent two years at lowa writing short stories, trying very hard to learn to write them. I sent one of them out. One of them was taken by the Beloit Fiction Journal, and then I wrote "Pipa's Story" during winter break. I revised it twice and sent it off to the Atlantic. They took it in March. Meanwhile, of course I was leaving the MFA program and I was working on many other things. I was lucky enough to be accepted into the Stegner program at Stanford which gave me more time to find my voice. If I hadn't had that I think it would have been very rough for me. After the story was printed in the Atlantic I got a lot of letters from editors asking me if I had a novel, suggesting something about mothers and daughters; it was 1993 and Amy Tan was very popular. I felt an enormous amount of resistance to the idea of writing something under contract at that time. I knew I didn't know what I was doing. I had only two years in an MFA program, and a year before that of trying to write. I also sensed that if too much attention was paid to me I would become too self-conscious. I didn't want to be called a writer before I was ready.

SE: Pearl S. Buck said, "I don't wait for moods. You accomplish nothing if you do that. Your mind must know it has got to get down to work." Can you speak about your writing practice? 
LSC: Well, when I am trying to work I try to write every morning first thing for a few hours. That has been the most productive way. Writing whether I feel it is right or whether I have something to say. On the other hand when I don't feel that I have something to say, that I have something to write, it is very difficult. That was the wonderful thing of writing a novel. I would know every morning when I went to write that it was waiting for me. I knew it was a mess, but it was there. Short stories are much more risky for me; you don't know if the story will still be there or whether it will self-destruct. But that makes it even more important for me to have a routine. Otherwise I just would shy away from it.

SE: What do you like most about your writing?

LSC: That's a really interesting question. Not all the time, but occasionally when I'm working on something, I get the sense that my characters are telling the truth. It's not necessarily the truth universally acknowledged. It's more of the truth to the circumstances that they are in, that which is usually not said. I suppose that's what I like about my writing, that it's an attempt to see human circumstances in an honest way, without bullshitting or putting on rose-colored glasses.

SE: I'm really struck by your one-word titles, and how much they resonate. At what point in your writing do you choose them?

LSC: I always choose them at the end. I've never written a book with a title in mind. Hunger was the title of the collection and my editor and I thought it was fine. Inheritance is an idea that Jill Bialosky, my editor, had, and I think it's a really good title. I was so up a creek in terms of titling this novel; I was working on it until the last minute. When she called it Inheritance I thought it sounded fine. Ideally I think I would have come up with a title that a Russian novel would have, such as The Sisters Chang, but one syllable last names are problematic.

SE: Where does your teaching fit into everything? 
LSC: I'm a very serious teacher. I have had the pleasure of teaching wonderful, brilliant students, in almost every school where I've taught. I've taught at the Iowa Writer's Workshop, I've taught at Harvard, and I've taught at the Warren Wilson MFA program for writers. For whatever reason, I've been lucky enough, probably because the institutions are so strong, to come across writers who inspire me, who make me think, and they keep me company and are an enormous pleasure to know. I find that teaching has become very important to me in a way I didn't expect. Of course, I come from a teaching family; maybe I'm just growing into my legacy.

SE: I understand you were once a student of Margot Livesey's. Can you talk about your experience as a student of writing in general, and more particularly as a student of Margot's?

LSC: I am not a person of great productivity, and so having teachers to guide me, particularly when I was starting out, was very important. They helped me mark time, to set timelines, they helped me see; they were older writers who provided solace, inspiration and faith. I think Margot is still the writing teacher who inspired me the most along these lines because she taught me to revise. She was always willing to look at my work and read it and tell me how she thought it could be made better, and then look at it again. She did this for a number of stories that are in Hunger. Going through this process with her, studying her marks on the page and going to conferences with her, I learned how to learn. She has been since then an extremely generous and humane source of support. I can't tell you how grateful I am to have worked with her.

SE: What have you learned not to do as a writer?

LSC: I suppose I've learned not to spell things out. I try not to focus on what's going to happen. I try not to be too critical of myself when I'm drafting, because it will stop me in my draft. I try not to be petty.

SE: As of today, who are your literary models, writers who have most astounded you? 
LSC: As of today the person who I'm most interested in is William Maxwell. I recently reread his book So Long, See You Tomorrow. I read it, my husband read it, we read it to each other and we talked about it. Maxwell does things in that book that l've never seen before, and in addition the book is so true to itself, it feels as if there's not a false step in it. I'd love to write something like that.

SE: Do you know what you're going to work on next?

LSC: I have three things I'd like to write. I'd like to write short stories, and a piece that's around 150 pages, and a longer novel. Of those projects the only one I know the topic of is a novel. It's going to be about poets. I'd also like to write about Asian Americans living in the Midwest. 